\title{
Educação Física nos primeiros anos do ensino fundamental: uma pesquisa sobre sua organização pedagógica em classe hospitalar ${ }^{1}$
}

\author{
Lisandra Invernizzi* \\ Alexandre Fernandez Vaz**
}

\begin{abstract}
Resumo: A Educação Física é uma disciplina que trata do corpo e suas expressões, condição presente também para as classes hospitalares, estruturas de atendimento pedagógico de crianças e jovens internados. A pesquisa analisou a organização do tempo pedagógico de uma experiência de ensino, considerando as temáticas Ginástica Geral, Jogos e Brincadeiras Tradicionais e Atividades Rítmicas e Expressivas. Durante seis semanas a prática foi organizada por ciclos semanais para cada temática, repetido depois de três semanas. Os dados foram coletados ao longo do planejamento, docência e avaliação das aulas, que foram observadas e registradas em caderno de campo. As categorias de análise escolhidas nos limites desse artigo são participação e inclusão e saúde e participação. Os resultados apontam para o sucesso da experimentação, mas alertam, entre outros aspectos, para a necessidade de mais conhecimento sobre as especificidades das doenças e os dispositivos de controle no ambiente hospitalar.

Palavras-chave: Criança hospitalizada. Adolescente hospitalizado. Jogos e brinquedos. Educação Física. Recreação.
\end{abstract}

\section{Prólogo - Educação Física em classes hospitalares?}

Classes Hospitalares são ambientes educacionais destinados ao atendimento pedagógico a crianças e jovens internados e, com isto, impedidos de freqüentar suas escolas de origem. No Brasil,

1 O trabalho é resultado parcial da pesquisa Convergindo olhares para alunos hospitalizados: conteúdos, metodologias e práticas, financiada pela FAPESC.

"Licenciada em Educação Física pela UFSC. Membro do Núcleo de Estudos e Pesquisas Educação e Sociedade Contemporânea (CED/UFSC/CNPq), Florianópolis, SC. Brasil. E-mail: lisandrainvernizzi@gmail.com

"* Doutor pela Universidade de Hannover. Professor do Programa de Pós-graduação em Educação e Educação Física da Universidade Federal de Santa Catarina (UFSC). Coordenador do Núcleo de Estudos e Pesquisas Educação e Sociedade Contemporânea (CED/UFSC/CNPq). Pesquisador CNPq. Florianópolis-SC, Brasil. E-mail:alexfvaz@pq.cnpq.br 


\section{Antifos Originais Lisandra Invernizzi, Alexandre Vaz}

surgiram com o intuito de dar continuidade à escolarização de crianças hospitalizadas, independente do tempo de internação (FONSECA, 2003). A legislação brasileira reconhece o direito de crianças e jovens hospitalizados ao atendimento pedagógico-educacional, como, por exemplo, por meio da Política Nacional de Educação Especial (BRASIL, 1994).

É com esse pano de fundo que, a partir de um convênio entre o Hospital Infantil Joana de Gusmão (HIJG), de Florianópolis, e as Secretarias de Educação e de Saúde do Estado de Santa Catarina, em agosto de 1999 foi implementada uma Classe Hospitalar vinculada à Escola Estadual Padre Anchieta. A classe destina-se ao atendimento de hospitalizados procedentes de todo o Estado de Santa Catarina e até mesmo de fora dele, com turmas de educação de quatro a seis anos, primeira a quarta e quinta à oitava série.

A Classe Hospitalar deve estar vinculada à uma escola regular de ensino, sendo dela uma extensão. Para cada aluno que freqüenta a classe, é preenchido um cadastro com dados pessoais, de hospitalização e da escola de origem. Ao término de cada aula a professora registra em ficha os conteúdos trabalhados e outras informações que julgar pertinentes. Para o aluno que freqüenta a classe por três dias ou mais, é necessário que se contate (via telefone) sua escola de origem, comunicando da sua participação nas atividades escolares no hospital e procurando obter informações referentes aos conteúdos que estariam sendo trabalhados naquele momento em sua turma. Ao receber alta hospitalar, é enviado à escola um relatório descritivo das atividades realizadas, bem como do seu desempenho, anotações sobre seu comportamento e dificuldades apresentadas.

A educação dos primeiros anos do Ensino Fundamental atende alunos de primeira à quarta série na mesma turma, dispondo hoje de três professoras, uma atuando em sala de aula e outras duas atendendo crianças impossibilitadas de se deslocar até a classe e que, por isso, são atendidas em seus leitos ${ }^{2}$.

\footnotetext{
${ }^{2}$ Atendimento pedagógico realizado no leito tem duração de 30 a 40 minutos com cada aluno, sendo de responsabilidade de professora que não é a mesma que atua na classe.

Mavimento, Porto Alegre, v. 14, n. 02, p. 115-132, maio/agosto de 2008.
} 
Considerando esse contexto, foi desenvolvida, em 2005, uma pesquisa cujo objetivo foi a busca de elementos para uma organização do trabalho pedagógico da disciplina Educação Física em séries iniciais do Ensino Fundamental em classe hospitalar. O tema da pesquisa não pode ser visto como "evidente", uma vez que chama atenção o fato de que as aulas de Educação Física geralmente são ministradas para alunos que não apresentam problemas de saúde ou com fins terapêuticos. Ao contrário dessa compreensão do registro do senso comum, optamos por considerar a Educação Física como um campo do conhecimento que trata da corporalidade ou das experiências corporais, de maneira que os temas tratados em seu interior pudessem ser duplamente conhecidos: pela apreensão corporal (técnica ou mimética), mas também pela possibilidade de uma aprendizagem que fosse além da prática e com vistas à compreensão dos fenômenos culturais que se expressam primordialmente pelo corpo e sua possível fruição cognitiva e estética.

\section{Aulas de Educação Física em Classe Hospitalar - uma PROPOSTA E SUAS DIFICULDADES}

Foram oferecidas aulas de Educação Física durante o período de seis semanas em dias alternados, ministradas por duas acadêmicas matriculadas na disciplina de Prática de Ensino de Educação Física Escolar II ${ }^{3}$. O objetivo era realizar as aulas em dois dias consecutivos, com vistas a tentar garantir uma certa continuidade temática e de público, uma vez que a rotatividade na classe é grande por conta das internações e altas e a frequiência a ela, ao contrário da escola regular, é facultativa. No entanto, acabamos por ministrar as aulas nas terças e quintas-feiras, o que pelo menos excluía as segundas e sextas-feiras, dias, respectivamente, de internação e alta e, portanto, de um número de internados mais reduzido.

As aulas foram organizadas na forma de ciclos compostos por três temáticas, desenvolvidas uma em cada semana, para, em

${ }^{3}$ Trata-se de uma disciplina curricular do curso de licenciatura em Educação Física da UFSC, com 108 horas-aula, ministrada no sétimo semestre.

Mavimento, Porto Alegre, v. 14, n. 02, p. 117-134, maio/agosto de 2008. 
seguida, serem retomadas na mesma ordem. Com os ciclos pretendíamos ao mesmo tempo dar sentido ao fato de que é preciso haver continuidade nos conhecimentos trabalhados em Educação Física, bem como contemplar, ao alcançar algum grau de conclusão a cada semana, alunos que permaneciam poucos dias hospitalizados. Isso reduzia o caráter episódico das aulas, algo infelizmente bastante comum nas práticas de Educação Física. O quadro 1 sintetiza a proposta levada a cabo:

\begin{tabular}{|l|l|l|l|}
\hline SEMANA & TEMA & SEMANA & TEMA \\
\hline Primeira & $\begin{array}{l}\text { Jogos e Brincadeiras } \\
\text { Tradicionais }\end{array}$ & Quarta & $\begin{array}{l}\text { Jogos e Brincadeiras Tradicionais } \\
\text { (b) }\end{array}$ \\
\hline Segunda & Ginástica Geral & Quinta & Ginástica Geral (b) \\
\hline Terceira & $\begin{array}{l}\text { Atividades Rítmicas e } \\
\text { Expressivas }\end{array}$ & Sexta & $\begin{array}{l}\text { Atividades Rítmicas e Expressivas } \\
\text { (b) }\end{array}$ \\
\hline
\end{tabular}

Quadro 1 - Proposta de programa das aulas de Educação Física na classe de hospitalizados.

A coleta de dados foi realizada entre $16 / 08$ e $22 / 09 / 2005^{4}$. A primeira temática, denominada Jogos e Brincadeiras Tradicionais, foi selecionada na tentativa de valorizar os saberes que os alunos já possuíam antes da frequiência à classe. Para a segunda temática, foi proposto o tema Ginástica Geral que, por sua vez, visava proporcionar experiências para conhecer seu próprio corpo e com diferentes possibilidades de movimento, valorizando uma das práticas clássicas da Educação Física Escolar. O tema Atividades Rítmicas e Expressivas foi proposto para a terceira temática. Procurávamos explorar manifestações que combinassem expressões e sons, como danças, mímicas e brincadeiras cantadas, já que, por meio delas, o aluno pode caracterizar diferentes movimentos expressivos, sua intensidade e duração.

Mesmo cientes de que o tempo pedagógico necessário para o desenvolvimento de uma atividade não deve depender apenas do professor, mas sim do trabalho desenvolvido com os alunos e tendo em mente que o planejamento não é uma camisa-de-força, optamos,

\footnotetext{
${ }^{4}$ Em um dos dias destinados à aula de Educação Física não houve atividade na classe, acarretando no desenvolvimento de apenas um encontro na primeira temática. Em relação às demais, aconteceu como previsto em duas aulas.

Mavimento, Porto Alegre, v. 14, n. 02, p. 115-132, maio/agosto de 2008.
} 
nos limites desse movimento de experimentação pedagógica, por não extrapolar o tempo previamente determinado de uma semana para cada ciclo.

Como as temáticas foram desenvolvidas em dois encontros semanais, na primeira aula era realizada uma explanação geral do que seria trabalhado. No início de cada encontro era anunciada uma síntese do que seria realizado, não só naquele, mas também no decorrer da respectiva temática. Ao partirmos para outro tema, quando estavam presentes alunos que participaram da aula anterior, era explanado brevemente o que fora realizado naquela, procurando sempre contar com a colaboração das crianças presentes.

Uma das dificuldades encontradas se relaciona à heterogeneidade da turma, tanto por seu caráter multiseriado, quanto pelas condições gerais de cada aluno. Considerando que cada criança se apresentava em situação singular e vivenciava experiências distintas, pois as dificuldades de uma não eram as da outra, na mesma aula poderíamos ter alunos com lesões traumáticas, fazendo quimioterapia, em período pós-cirúrgico ou até mesmo um que estava apenas internado para realizar alguns exames, não aparentando portar qualquer enfermidade.

Outro fator considerado foi que os alunos, algumas vezes, chegavam após o início das atividades ou necessitavam sair antecipadamente em função do tratamento médico, obrigando-nos, constantemente, a elaborar estratégias de inclusão. No primeiro caso, propúnhamos que os que estavam presentes colaborassem para familiarizar o colega com o que estava sendo realizado e, no segundo, sugeríamos um meio para que finalizassem a atividade, na classe ou em outro momento em que pudesse e desejasse.

No sentido de considerar a Educação Física como disciplina importante para a formação das crianças, propusemos atividades extraclasse, geralmente de pesquisa tipo escolar. Acreditávamos que esta tarefa não seria fácil de ser operacionalizada, visto que, em escolas regulares, os alunos costumeiramente levam para casa tarefas de todas as disciplinas, menos de Educação Física. Não foi o caso, como será visto. Outro fator limitante foi o ambiente que, por se

Mavimento, Porto Alegre, v. 14, n. 02, p. 117-134, maio/agosto de 2008. 
tratar de um hospital, tornava mais difícil a locomoção, seja por impossibilidades motoras ou mesmo por certo constrangimento pela condição de paciente ${ }^{5}$.

\section{Retratos dA EXPERIÊNCIA PEDAGóGICA}

Analisando as informações sobre os dois ciclos completos que constam no detalhado diário de campo, e também de posse dos relatórios das estagiárias que ministraram as aulas, foi possível categorizar e analisar a experimentação pedagógica realizada em quatro eixos temáticos sintetizadores da experiência: a)Processos de participação e inclusão; b)Diferenças nos tempos de ensino e de aprendizagem; c)Conhecimento prévio das crianças e organização das aulas; d)Saúde, incertezas, participação. Considerando os limites do presente texto e a riqueza dos resultados obtidos, trataremos aqui apenas do primeiro e do último eixo temático.

\subsection{Participação e inclusão}

A participação foi uma das questões que tornou possível organizar uma narrativa em torno da prática pedagógica analisada. Consideramos que ela acontecia quando as crianças realizavam as atividades propostas, ativa ou passivamente, com possibilidades de papéis diferenciados entre os atores. Participar é, de alguma forma, tomar parte do processo decisório, das discussões. Vejamos como isso pôde acontecer em várias das aulas.

Na segunda aula referente à temática Atividades Rítmicas e Expressivas, no primeiro ciclo, desde o instante em que entrou na sala, um menino alegava que não queria participar. Percebendo isto, as estagiárias utilizaram diversas estratégias inclusivas para convencê-lo. Fundamental foi o convite constante, que resultou em pequenas

\footnotetext{
${ }^{5}$ Destaque-se que a condição de paciente supõe, via de regra, uma certa menoridade expressa na total submissão ao corpo de especialistas e ao saber clínico e médico. Além disso, o paciente perde a autonomia sobre seu próprio corpo que deve deixar-se ser alvo de tratamentos diversos que ignoram o sujeito expondo-o a experiências possivelmente incomuns, como a nudez frente a pessoas estranhas.
}

Mavimento, Porto Alegre, v. 14, n. 02, p. 115-132, maio/agosto de 2008. 
incursões nas atividades. Nestas, ele fazia parte da tomada de decisões, colaborava com as escolhas, até que o convite se tornou desnecessário.

Em outras situações, mesmo que a criança quisesse participar, não poderia fazê-lo de forma idêntica aos colegas, tendo em vista as limitações individuais e, também, é importante destacar, o fato de que tomamos como razoável que todos os alunos devam realizar as mesmas atividades designadas por um padrão de "normalidade" que é em si mesmo bastante questionável. O soro na mão, braço engessado, movimentos impossibilitados em função de cirurgias, entre outras questões, limitavam a participação dos alunos. Nestes momentos sugeríamos a realização de papéis distintos na atividade, pois mesmo que não fizessem o mesmo que o colega realizavam outra função, garantindo, desta forma, uma participação nas ações coletivas. No diário de campo há registros de diversas situações que descrevem estes momentos de inclusão: bolinhas e um menino, que estava com soro em uma das mãos e por isso impossibilitado de construir sozinho, participava da atividade modelando, dando forma para o brinquedo. (Diário de Campo, dia 23 ago. 2005).

Primeiramente deveriam jogar a bolinha para o alto e bater palma, com exceção do menino com o soro na mão que tocaria a mão no nariz... (Idem).

Na aula havia um menino com o braço engessado e, por ser o mais alto, pegava os balões para os colegas. (Diário de campo, 31 ago. 2005).

A participação/inclusão foi mais problemática principalmente no primeiro ciclo, pois, na medida em que as aulas iam acontecendo, notava-se que era um aspecto que merecia atenção, já que sempre havia uma criança que, em princípio, renunciava a participar.

No segundo ciclo não houve problemas em relação à participação, ocorrendo apenas situações em que era necessário incluir a criança na atividade, o que foi, surpreendentemente, realizado com êxito em todas as situações. Para exemplificar, recorremos ao diário de campo:

Mavimento, Porto Alegre, v. 14, n. 02, p. 117-134, maio/agosto de 2008. 
A atividade iniciou com apenas um balão, o que de certa forma acabou por não incluir todas as crianças. Percebendo isto, para que todos pudessem participar, as estagiárias acrescentaram mais balões, até que todos estavam envolvidos na brincadeira. (Diário de campo, 8 set. 2005).

Na mesma aula, outra situação demonstra como as estagiárias lidaram no momento em que duas crianças abdicaram de participar:

[...] duas crianças não quiseram participar, alegando não gostarem de estourar balão. [...] Para que todos participassem, a sugestão foi que o rabinho de balão fosse substituído pelo de papel preso na cintura. (Diário de campo, 8 set. 2005).

$\mathrm{Na}$ Classe Hospitalar é corriqueiro ocorrerem alguns impedimentos que fazem com que a criança, mesmo manifestando o desejo de participar, não o faça devido a questões como estar vivenciando um período pós-cirúrgico, limitações nos movimentos causados por talas, soros, agulhas, situações que causam dor, entre outras possibilidades. Nestas circunstâncias, torna-se necessário flexibilizar o planejamento e mostrar alguma capacidade de improvisação para que a situação seja contornada e o aluno participe das atividades. De acordo com o diário de campo:

Uma menina que havia realizado uma cirurgia não participou correndo, mas controlava quem ficava por tempo excessivo na barra e quem era o pegador. (Diário de campo, 9 set. 2005).

O soro na mão de uma menina impedia que fizesse a tarefa como os colegas, no entanto, não a excluía da atividade, já que estava incumbida de moldar as bolinhas, de deixá-las no formato redondo. (Diário de campo, 13 set. 2005).

Com os exemplos acima é possível compreender que nas atividades os alunos podem desempenhar papéis diferenciados, não significando necessariamente que um participe mais e outro menos, desde que as atividades não estejam centralizadas em estruturas competitivas, algo ainda bastante comum, ainda que como paródia

Mavimento, Porto Alegre, v. 14, n. 02, p. 115-132, maio/agosto de 2008. 
(BASSANI; TORRI; VAZ, 2003) ${ }^{6}$ nas aulas de Educação Física e esperado por muitos alunos que freqüentam a classe quando ficam sabendo que haverá aulas da disciplina. No segundo exemplo, a atividade que a menina desempenhou também é importante e nada impedia que ela, ou mesmo outra das crianças, ocupasse aquele lugar social. É importante, no entanto, que os papéis não sejam hierarquizados, ou reproduziremos uma situação perversa da escolarização, que é a de destinar a alguns impossibilitados por algum motivo - sua falta de habilidade ou força, por exemplo - um papel secundário e consolador nas atividades.

Como já foi destacado, um dos objetivos da educação em Classes Hospitalares é a inclusão das crianças e adolescentes que, por estarem internados, não podem frequientar as aulas nas escolas de origem. Desta forma, a inclusão que deve ocorrer nas aulas da Classe Hospitalar seria uma espécie de inclusão da inclusão, visto que a Classe Hospitalar é uma modalidade que faz parte, segundo a Lei de Diretrizes e Bases da Educação Nacional, da Educação Especial.(BRASIL, 1996)

A suposição inicial de que as crianças relutariam em participar das aulas justamente por ser de Educação Física, uma vez que vários deles, em situações que observamos antes da pesquisa, já eram excluídos das aulas dessa disciplina em suas escolas de origem por conta de suas precárias condições de saúde, não se confirmou. Apresenta-se um dos paradoxos interessantes da escolarização, em especial da Educação Física, uma vez que se diz com freqüência que sua prática é benéfica para a saúde, ao mesmo tempo em que muitas vezes se exclui aqueles que não apresentam "boas" condições de saúde para sua prática.

Trabalhar com a diversidade implica numa abertura para o novo e o distinto, em um enfrentamento do impacto causado pela

${ }^{6} \mathrm{O}$ que muitas vezes presenciamos é uma espécie de simulacro do esporte convencional, uma vez que as condições objetivas para sua realização, nas aulas de Educação Física, não estão colocadas. Como com freqüência o esporte não é ressignificado para que possa ser de fato um tema a ser ensinado nas aulas, resta a cópia desbotada do esporte-espetáculo.

Mavimento, Porto Alegre, v. 14, n. 02, p. 117-134, maio/agosto de 2008. 


\section{Astifos Origimais Lisandra Invernizzi, Alexandre Vaz}

deficiência que toca no nosso sentimento de onipotência e na construção de uma noção compartilhada de deficiência. Todos nós apresentamos dificuldades que devemos superar, visto que, como educadores, trabalhar com a diversidade demanda, ainda, um comprometimento com este trabalho, coragem, curiosidade científica e interesse (LIMA, 2002). Trata-se de um reconhecimento da pluralidade.

Em todas as aulas a proposta foi trabalhar a mesma atividade para todos os alunos, ainda que, sempre que necessário, com papéis diferentes. Talvez tivesse sido o momento de avançar em relação à proposta e experimentar atividades distintas ocorrendo simultaneamente, ou seja, propor que nas aulas duas atividades fossem desenvolvidas simultaneamente por crianças diferentes. Desta forma, enquanto uma estagiária explicasse para um grupo, a outra ficaria responsável em ministrar uma dinâmica distinta para os demais alunos. Isto seria facilitado em função de duas estagiárias ministrarem a aula. O número reduzido de alunos pode ser considerado como positivo para a realização de atividades distintas, pois as orientações podem ser mais individualizadas. Por outro lado, pode apresentar um problema, caso a proposição de uma atividade acentue alguma estigmatização.

A organização dos temas em ciclos temáticos visava minimizar o problema da eventual falta de participação. Observamos que a decisão parece ter sido acertada, já que, como previam os elementos teórico-metodológicos, a repetição da temática seria uma possibilidade para avançar em relação à primeira intervenção. Por meio da análise, reflexão e re-planejamento das atividades foi possível, por exemplo, contornar momentos da não participação presentes no primeiro ciclo.

\subsection{Saúde, incertezas, participação}

Atrelada à problemática da participação, em alguns momentos das intervenções nos deparamos com situações que nos fizeram considerar mais proximamente sua relação com a saúde das crianças. Tendo em vista que estavam no hospital prioritariamente para tratamento médico, era evidente que apresentassem limitações para

Mavimento, Porto Alegre, v. 14, n. 02, p. 115-132, maio/agosto de 2008. 
realizarem algumas atividades - assim como, aliás, as crianças consideradas saudáveis também apresentam algo muito visível nas aulas de Educação Física. Desta forma, pode tornar-se inadequado e mesmo perigoso, em algumas situações de aula, a proposição de um ritmo mais intenso ou até mesmo um movimento que porventura possa prejudicar a recuperação ou o tratamento de uma criança. $\mathrm{Na}$ primeira aula, na realização de uma atividade que envolvia bastante movimentação, ocorreu a seguinte situação: "Nesta atividade as crianças demonstraram entusiasmo, sendo considerado o pico da aula, já que os alunos se movimentaram até evidenciarem fadiga física." (Diário de campo, 16 ago. 2005).

Nas primeiras aulas ocorreram dois episódios em que, dada a agitação da turma, houve choque entre duas crianças, sendo que uma estava com soro e o resultado foi dor. Além disso, há de se pensar sobre as limitações que alguns podem apresentar em relação a determinados movimentos como, por exemplo, dores resultantes da aplicação de injeções. Para que os acontecimentos não se repetissem nas aulas seguintes, as estagiárias passaram a solicitar cautela nas atividades. Mesmo assim, algumas vezes as crianças estavam bastante agitadas, talvez porque naquele momento se configurasse uma das poucas ocasiões em que se movimentavam de forma mais livre, subvertendo a ordem a que estão expostas no hospital:

Apesar de diversas vezes as estagiárias solicitarem calma, as crianças continuaram agitadas, correndo, algumas ofegantes e demonstrando cansaço. (Diário de campo, 25 ago. 2005).

Apesar das diversas manifestações e pedidos de calma por parte das estagiárias, as crianças continuaram agitadas, até que, semelhante ao fato da aula anterior, um menino agitado bateu na mão em que estava o soro do colega, resultando em dor. (Diário de campo, 25 ago. 2005).

As informações acerca de cada aluno eram obtidas nas enfermarias e, principalmente, nas conversas com a professora da turma antes das aulas, que nos comunicava sobre as condições dos que já haviam freqüentado a classe e sobre as quais, portanto, fizera o

Mavimento, Porto Alegre, v. 14, n. 02, p. 117-134, maio/agosto de 2008. 


\section{Astifor Orifinais Lisandra Invernizzi, Alexandre Vaz}

cadastro com vários dados, incluindo os motivos de internação, sempre por meio de perguntas dirigidas a eles, cujo conhecimento da extensão da enfermidade que os acometia nem sempre era vasto.

Na primeira aula, quando foi proposta a atividade da "Dança das Cadeiras", um aluno respondeu da seguinte maneira: "Eu não quero, não vou me matar."

Naquela situação consideramos que a manifestação poderia ser observada como uma tentativa de auto-preservação, tendo em vista suas condições de saúde, e percebemos que o menino considerava se a atividade poderia ou não causar algum malefício a ele. Em uma ocasião semelhante que exigia movimentação intensa: [...] "uma menina realizou com cautela, em função de estar em período pós-operatório. Mesmo impossibilitada de realizar alguns movimentos, ela participou de toda aula, da maneira que lhe foi possível." (Diário de campo, 15 set. 2005).

Ao término do primeiro ciclo analisou-se se havia ou não a necessidade de reestruturação do planejamento das aulas. Em função da problemática das atividades relacionadas à saúde, sobre os benefícios ou malefícios que algumas poderiam ocasionar, no segundo ciclo as estagiárias optaram por excluir do planejamento uma prática que no primeiro foi bastante agitada e ao fim da qual os alunos apresentaram fadiga, tendo estado ofegantes e bebendo água algumas vezes durante a dinâmica. Naquela ocasião, avaliamos que: "Foi uma opção de cautela por parte das estagiárias, pois naquela aula, de nada adiantou solicitar que as crianças tivessem calma, inclusive acontecendo que uma delas se chocou com um colega que estava com soro, e que resultou em dor para aquele." (Diário de campo, 15 set. 2005).

Dadas as peculiares e evidentes condições de saúde em que as crianças se encontram em um hospital, havia especificidades na participação nas atividades. Aparatos que os alunos carregam compulsoriamente, como gesso, tala, agulhas, cadeira de rodas, haste para o soro, coletor urinário, são balizas a serem consideradas no desenvolvimento das aulas.

Mavimento, Porto Alegre, v. 14, n. 02, p. 115-132, maio/agosto de 2008. 
Além disso, outro condicionante é o tratamento médico, pois algumas vezes a criança está impossibilitada de participar da aula por estar em período pré ou pós-cirúrgico ou em função da realização de exames no mesmo horário da aula, apresentando não apenas alguma debilidade física e/ou emocional, mas acontecendo até mesmo de se retirar no decorrer das atividades, às vezes retornando, outra vezes, não.

\section{Algumas considerações}

A inserção da Educação Física em Classes Hospitalares é algo muito recente, e no Hospital Infantil Joana de Gusmão data seu início do segundo semestre de 2003. O presente trabalho procurou ser uma resposta a alguns embates da organização pedagógica da Educação Física Escolar, tomando como referência a experiência de uma classe hospitalar.

A organização em ciclos temáticos procurou minimizar algumas dificuldades encontradas em nossa experiência, como a combinação entre rotatividade de alunos e permanência de outros e, ainda, a problemática da organização dos conhecimentos em uma ordenação que favorecesse a aprendizagem - algo que permanece como desafio para a Educação Física escolar de forma geral.

As questões centrais giraram em torno da participação dos alunos, um tema controverso na educação escolar, em especial na Educação Física. Um exemplo disso é o fato de que nem sempre os alunos esperam com tanto fervor as aulas de Educação Física, como diz o senso comum, mas procuram, sim, evadir-se das aulas em sala (VAZ; BASSANI; SILVA, 2002). Na classe hospitalar isso está parcialmente contornado pelo caráter voluntário da freqüência às aulas. Mas, por outro lado, a participação se relaciona a dois outros aspectos: a)exposição a movimentos corporais nem sempre facilitados pelos equipos e b)necessidades de tratamento, limitações impostas pelas condições de saúde às vezes precárias.

A isso se coloca a exigência de um conhecimento menos superficial das condições de saúde dos alunos. Havíamos proposto

Mavimento, Porto Alegre, v. 14, n. 02, p. 117-134, maio/agosto de 2008. 
que antes do início de cada aula as estagiárias lessem os prontuários dos possíveis alunos visando um pré-conhecimento das limitações para aquela intervenção, para que, se necessário, adaptassem ou excluíssem atividades porventura inadequadas. Naquele momento, no entanto, e ao contrário do que já acontecera em outras oportunidades, não foi possível consultá-los. Desta forma, limitamos nossas informações acerca dos alunos às respostas obtidas nas enfermarias ou da professora da classe, o que torna o conhecimento das doenças ainda mais restrito, além da falta de recursos teóricos e práticos que já apresentávamos.

Há aqui uma dupla problemática: o hospital não é, deliberadamente, um espaço pedagógico (embora seja portador de uma pedagogia de disciplina e controle dos corpos), de maneira que as questões educacionais acabam por ser relegadas ao segundo plano; por outro lado, há uma indicação do serviço pedagógico do hospital de que não se devem discutir as enfermidades dos alunos em sala, a menos que a demanda parta deles. Entendemos, no entanto, que isso deve ser questionado, uma vez que pode haver, por meio desse procedimento, algo como um recalque de condições objetivas que interferem diretamente na subjetividade dos alunos.

Por outro lado, de nada adianta o professor/estagiário ter acesso livre aos prontuários se não compreender o que estiver escrito em tal documento. Há que se considerar que os educadores precisam ter um conhecimento mínimo sobre diferentes enfermidades e procedimentos médicos, mas, sobretudo, que deve haver interação da equipe de saúde e de que dela deva, de alguma modo, participar o educador.

A rotatividade e heterogeneidade da turma, algo já visto em outras situações (VAZ; VIEIRA; GONÇALVES, 2005) fizeram-se presentes na experiência pesquisada, demonstrando que são problemáticas típicas em tal ambiente. Sobre a primeira não há muito que possa ser feito, já que não depende do professor e nem do aluno, mas sim das circunstâncias. O que pode ser pensado é a organização dos conteúdos em forma de temáticas que tenham uma finalidade em um ciclo mais curto e em dias seguidos, ou ainda um investimento

Mavimento, Porto Alegre, v. 14, n. 02, p. 115-132, maio/agosto de 2008. 
em atividades e ritmos diferenciados que contemplem alunos com diferentes tempos de permanência no hospital e na classe.

Também em relação à heterogeneidade devemos avançar na proposta de atividades distintas ocorrendo simultaneamente na mesma aula e na experimentação de papéis distintos nas dinâmicas. Como na turma há crianças de $1^{\mathrm{a}}$ a $4^{\mathrm{a}}$ séries, e conseqüentemente, com idades, capacidades, limitações etc. diferenciadas, indicar as mesmas atividades pode significar a reafirmação de um problema presente na escolarização regular, em que um aluno da $5^{\mathrm{a}}$ série participa sem problema algum de uma aula de Educação Física para a $8^{\mathrm{a}}$ série, tirando as diferenças de capacidade física dadas pela maturidade. O sério problema na organização curricular que aí se vê denunciado é a falta de conexão e progressão na aprendizagem e na experimentação de conhecimentos em Educação Física. Quando colocamos que na mesma situação devem acontecer diferentes atividades, não estamos aderindo a um hiper-individualismo que infirmaria práticas coletivas, mas predicando que em alguns momentos possa ser interessante experimentar a idéia por um tempo que possa ser suficiente para fins de avaliação e reflexão.

Ao elaborarmos os elementos balizadores, sinalizamos que dificilmente os alunos que participassem de uma temática no primeiro ciclo estivessem presentes na respectiva aula no segundo ciclo. E realmente foi o que ocorreu, já que não tivemos a presença de nenhuma criança por duas vezes na mesma temática. Desta forma, a organização em forma de ciclos é considerada por nós como um bom elemento norteador, já que permite que as intervenções sejam pensadas e refletidas para uma nova experimentação, visando sempre avançar em relação ao que foi efetivado. Por outro lado, tivemos várias experiências com crianças nas duas aulas de uma semana, mostrando algo de acertado em nossa opção.

Podemos supor que a organização em forma de ciclos temáticos é uma alternativa possível para o ensino da Educação Física em Classes Hospitalares. Sugerimos que em pesquisas posteriores sejam acrescentadas mais temáticas aos ciclos. Propomos também que sejam desenvolvidos três ciclos para que possa ser 
possível a reelaboração e reestruturação das aulas, no sentido de avançar em relação ao já alcançado, confirmando ou ponderando os resultados de dois ciclos e diminuindo a casualidade das experiências.

Por fim, é preciso destacar o caráter provisório das considerações aqui apresentadas, lembrando, ainda, que mais algumas devam ser incorporadas às pesquisas, entre elas a consideração pelos temas a serem trabalhados em Educação Física Escolar, a condição social da experiência de ser criança - algo que não está excluído da experiência hospitalar - e o vínculo que esses alunos estabelecem com a Educação Física que vivenciam em suas escolas de origem.

Mavimento, Porto Alegre, v. 14, n. 02, p. 115-132, maio/agosto de 2008. 
Physical Education in the First Years of Elementary School: a Research on its Pedagogical Organization in a Hospital School Class.

Abstract: Physical Education is the school discipline of body and is expressions, something that is also present in hospital school class. The research analyzed pedagogical time organization in a teaching experience, observing three themes: General Gymnastic, Traditional Games and Rhythmical and Expressive Activities. On six weeks the pedagogical praxis was done through weekly cycles, restarted after three weeks. The data were collected during planning, teaching and evaluation. The classes were observed and described on notebooks. The analytic categories described in this paper are Participation and Inclusion and Health and Participation. The results show the successful of the experience, but they warn, under other questions, about the necessity of a deeper knowledge about the characteristics of the sickness and about the control mechanisms in Hospital.

Keywords: Child, hospitalized. Adolescent, hospitalized. Play and playthings. Physical Education. Recreation.

Educación Física en los primeros años de la escuela fundamental: una investigación sobre su organización pedagógica en turma hospitalaria

Resumen:La Educación Física es una disciplina que trata del cuerpo y sus expresiones, algo presente también en las turmas hospitalarias, estructuras para el trato pedagógico de niños y jóvenes internados. La investigación analizó la organización del tiempo pedagógico de una experiencia de enseñanza, teniendo en cuenta las temáticas Gimnástica General, Juegos Tradicionales y Actividades Rítmicas y Expresivas. Durante seis semanas la práctica fue organizada por ciclos semanales para cada temática, repetido después de tres semanas. Los datos fueran colectados al largo del planeamiento, docencia y avaluación de las clases, que fueran por su vez observadas y registradas en cuaderno de campo. Las categorías de análisis elegidas nos límites de este artículo son participación y inclusión y salud y participación. Los resultados apuntan para la buena consecución de la experimentación, pero alertan, entre otras cuestiones, para la necesidad de más conocimiento sobre las especificidades de las enfermedades y los dispositivos de control en el ambiente hospitalario.

Palabras-clave: Niño hospitalizado. Adolescente hospitalizado. Juego e implementos del juego. Educación Física. Recreación.

Mavimento, Porto Alegre, v. 14, n. 02, p. 117-134, maio/agosto de 2008. 


\section{REFERÊNCIAS}

BASSANI, J. J.; TORRI, D.; VAZ, A. F. Sobre a presença do esporte na escola: paradoxos e ambigüidades. Movimento, Porto Alegre, v. 9, n. 2, p. 89-212, 2003.

BRASIL. Ministério de Educação e do Desporto. Secretaria de Educação Especial. Política Nacional de Educação Especial: livro 1. Brasília: MEC, 1994.

BRASIL. Lei n. 9394, de 20 de dezembro de 1996: Lei de Diretrizes e Bases da Educação. Diário Oficial da República Federativa do Brasil. Brasília, DF, n. 248, 23 dez 1996.

FONSECA, E. S. da. Atendimento escolar no ambiente hospitalar. São Paulo: Memon, 2003.

LIMA, P. A. Educação inclusiva e abordagem sócio-histórica. In: Seminário: as perspectivas de inclusão de pessoas com necessidades especiais, 2002, Belo Horizonte. Anais.... Belo Horizonte, 2002. p. 39-42.

VAZ, A. F. ; VIEIRA, C. L. N. ; GONÇALVES, M. C. Educação do corpo e seus limites: possibilidades para a Educação Física na classe hospitalar. Movimento, Porto Alegre, v. 11, n. 1, p. 71-87, 2005.

VAZ, A. F.; BASSANI, J. J.; SILVA, A. S. da. Identidades e rituais na educação do corpo na escola: um estudo em aulas de Educação Física no Ensino Fundamental. Motus Corporis, Rio de Janeiro, v. 9, n. 2, p. 23-39, 2002.

Pesquisa financiada pelo CNPq. O projeto foi aprovado pelo Comitê de Ética em Pesquisa em Seres Humanos da UFSC. 